\title{
Resenha do livro Coleta de Dados Qualitativos: Um Guia Prático para Técnicas Textuais, Midiáticas e Virtuais
}

\author{
Review of the book Qualitative Data Collection: A Practical Guide to \\ Textual, Media and Virtual Techniques
}

\author{
Reseña de libro Recopilación de Datos Cualitativos: Una Guía Práctica \\ de Técnicas Textuales, Mediáticas y Virtuales
}

\begin{abstract}
COLETA DE DADOS QUALITATIVOS: UM GUIA PRÁTICO PARA TÉCNICAS TEXTUAIS, MIDIÁTICAS E VIRTUAIS. Braun V, Clarke V, Gray D. Petrópolis: Editora Vozes; 2019. 385 p. ISBN: 978-85-326-6060-2.
\end{abstract}

doi: 10.1590/0102-311X00314920

A Internet e o desenvolvimento de aplicativos que envolvem mais o usuário abriram um mundo totalmente novo para pesquisadores, seja na utilização da rede como meio de acesso a potenciais participantes do estudo, seja na inclusão das informações produzidas aí como fonte de dados para pesquisa em saúde 1 . Adicionalmente, a COVID-19 acelerou a implementação das tecnologias digitais no aprimoramento das estratégias de saúde pública relacionadas à telessaúde 2 .

Por outro lado, a compreensão do processo saúde-doença exige não apenas conhecimento de dados epidemiológicos, mas também de pesquisas sobre a percepção da doença, práticas sociais relacionadas às formas de transmissão, comportamentos de busca de saúde, oferecimento e barreiras de acesso aos serviços. Para um melhor entendimento de tais dimensões de respostas a surtos de doenças infecciosas, as pesquisas qualitativas têm um robusto histórico de contribuição ${ }^{3}$. No entanto, o distanciamento social impõe enormes restrições de acesso ao campo para o investigador qualitativo. Neste contexto, o livro
Coleta de Dados Qualitativos: Um Guia Prático para Técnicas Textuais, Midiáticas e Virtuais ganha relevância por constituir um resumo das novas formas de utilizar plataformas digitais na coleta de dados em pesquisa qualitativa. Embora lançado em 2019, o livro oferece uma rica contribuição ao momento atual por tratar, com profundidade, da utilização de fontes de dados virtuais e de mídia na produção do conhecimento científico.

Pesquisadores iniciantes na pesquisa qualitativa em saúde frequentemente têm dúvidas sobre como transferir o conhecimento acerca da coleta de dados offline para um ambiente online 4 . Neste livro, as autoras propõem diretrizes de melhores práticas, com base na literatura e em sua própria experiência, para ajudar estudantes e pesquisadores iniciantes a determinar se um desenho de estudo qualitativo online é apropriado para seu projeto de pesquisa e, em caso positivo, fornecer dicas práticas de como implementá-lo. O principal objetivo é propor referências de fácil compreensão para a coleta de dados qualitativos em diferentes contextos, especialmente nos meios virtuais.

O texto é dividido em três partes temáticas, cada qual tratando de um tipo de fonte de dados. As partes são divididas em quatro capítulos, com autores distintos, especialistas nos métodos que apresentam. A primeira trata da coleta de dados textuais (capítulos 2 a 5), a segunda, da coleta de dados da mídia (capítulos 6 a 9) e a terceira enfoca coleta de dados virtuais (capítulos 10 a 13). Nota-se muitas vezes sobreposição entre 
as partes, pois os dados textuais e de mídia são frequentemente acessados online. A ênfase é na coleta de dados, em detrimento dos modos diferentes de análise.

Inicialmente as autoras introduzem os leitores nos fundamentos da coleta de dados textuais, midiáticos e virtuais da pesquisa qualitativa. $\mathrm{O}$ capítulo 2 aborda os "levantamentos qualitativos", nos quais os participantes respondem por escrito um conjunto de perguntas abertas sobre experiências e práticas de determinados grupos. As autoras apresentam sua experiência prática com levantamentos "puramente" qualitativos e com levantamentos mistos, sugerindo orientações para coletar dados por meio destes instrumentos. No capítulo 3, os autores apresentam o "preenchimento de histórias", ferramenta tradicionalmente conhecida como método projetivo na psicologia, mas que aqui é trazida como uma estratégia criativa para conhecer visões e opiniões dos entrevistados sobre questões de gênero, sexualidade e aparência. No capítulo 4, as "vinhetas como método qualitativo e independente" são apresentadas como caminhos possíveis para compreender o processo de construção de sentidos pelos participantes da pesquisa. No capítulo 5 , é proposto aos participantes da pesquisa digitar sua resposta por meio do "método do diário solicitado". Trata-se de uma ferramenta potente para a compreensão de experiências pessoais em uma pesquisa longitudinal.

O capítulo 6 explora diferentes mídias (mídia impressa, mídia social e online) como importantes fontes de dados para pesquisa qualitativa no mundo contemporâneo, oferecendo roteiros práticos para o trabalho com esses tipos de dados. O capítulo 7 apresenta o "rádio falado" como potente fonte de dados para pesquisadores interessados nos diversos aspectos da linguagem e da interação através da fala. No capítulo 8 , o autor trata dos blogues como recursos importantes de acesso a relatos em primeira pessoa sobre temas cotidianos. O capítulo 9 destaca o papel dos "fóruns de discussão" online como fonte de relatos, visões e experiências pessoais, que permitem também compreender processos de interação e formação de identidades sociais. Aqui também se problematizam questões éticas relacionadas a esta fonte de dados obtidos online.

A parte três interessa especialmente a pesquisadores que tiveram projetos interrompidos pelo distanciamento social. As autoras se concentram na coleta de dados virtuais obtidos de formas interativas, isto é, entrevistas e grupos focais online. Detalham diversos aspectos avaliados na opção por entrevistas individuais ou grupos focais, problematizando o uso de métodos síncronos ou assíncronos, além da utilização exclusiva de material textual ou da inserção de elementos da mídia visual. Destacam inúmeras vantagens dos métodos virtuais como: "superação da distância", "facilidade e flexibilidade de agendamento", "conveniência para pesquisadores e participantes", "interação visual e virtual”, "possibilidade maior de anonimato", "facilidade de captura de dados" e "confidencialidade de dados e facilidade". Apontam os desafios relativos à confidencialidade da coleta de dados em espaços virtuais. Exploram o uso das tecnologias de chamadas por vídeos (em plataformas tipo Skype - https://www.skype.com/pt-br/) para conduzir entrevistas virtuais que integram dados visuais. Examinam as diferenças entre entrevistas orais presenciais e entrevistas escritas virtuais. No capítulo final, as autoras descrevem o universo da pesquisa com grupos focais online. Consideram vantagens desta estratégia, apresentando-a como mais inclusiva para determinados grupos sociais. Descrevem vantagens e desvantagens desta fonte de dados como meio de capturar as vozes de grupos difíceis de alcançar.

Em resumo, o texto apresenta uma coletânea inédita de métodos para levantar dados, registrar e empregar o espaço virtual como fonte de dados qualitativos. Condições impostas pela pandemia aceleraram a necessidade de compreender a natureza deste tipo de pesquisa, que nos permite comunicação e acesso a uma diversidade de pessoas, com um custo baixíssimo. O que estas ferramentas oferecem ao investigador no campo da pesquisa qualitativa? Quais perguntas de pesquisa são adequadas a este tipo de entrevista? Exis- 
tem especificidades de desenho, amostragem, questões éticas? O que pode "dar errado"? Quais tipos de análise são mais adequados ao universo da pesquisa online? O livro responde de maneira clara e objetiva a questionamentos como estes, constituindo leitura necessária e agradável no contexto atual.

\section{Carmen Santana 1}

1 Universidade Federal de São Paulo, São Paulo, Brasil. carmen.santana@unifesp.br

\section{Informação adicional}

ORCID: Carmen Santana (0000-0002-6148-6230).

1. Biedermann N. The use of Facebook for virtual asynchronous focus groups in qualitative research. Contemp Nurse 2018; 54:26-34.

2. Caetano R, Silva AB, Guedes ACCM, Paiva CCN, Ribeiro GR, Santos DL, et al. Desafios e oportunidades para telessaúde em tempos da pandemia pela COVID-19: uma reflexão sobre os espaços e iniciativas no contexto brasileiro. Cad Saúde Pública 2020; 36:e00088920.

3. Vindrola-Padros C, Chisnall G, Cooper S, Dowrick A, Djellouli N, Symmons SM, et al. Carrying out rapid qualitative research during a pandemic: emerging lessons from COVID-19. Qual Health Res 2020; 30:2192-204.

4. Wilkerson JM, Iantaffi A, Grey JA, Bockting WO, Rosser BR. Recommendations for internet-based qualitative health research with hard-to-reach populations. Qual Health Res 2014; 24:561-74. 